\title{
AÇÃO AFIRMATIVA, AUTORITARISMO E LI'BERALISMO NO BRASIL DE 1968
}

\author{
ANTonio SÉrgio Alfredo GuimarÃes
}

\section{RESUMO}

Em 1964, um golpe militar pôs fim à experiência democrática brasileira do período pós-guerra. No governo de transição que se seguiu, ancorado em uma aliança entre os militares e políticos da direita liberal, surgiu a primeira tentativa de reconhecer a existência de discriminação racial sistemática no país e de implementar medidas de ação afirmativa para corrigi-la. Isso aconteceu em novembro de 1968, pouco antes de os militares romperem seu compromisso liberal e institucionalizarem um regime militar autoritário que durou mais dezessete anos. Usando principalmente documentos de época, como jornais diários, o artigo analisa a conjuntura política que permitiu que cotas fossem propostas, e posteriormente rejeitadas pelos militares, cristalizando a "democracia racial" como ideologia do regime. São analisadas principalmente as forças sociais que poderiam ancorar a proposta de ação afirmativa, e aquelas que reagiram e abortaram a sua discussão.

Palavras-Chave: cotas, autoritarismo, liberalismo, regime militar.

\section{ABSTRACT}

In 1964 a military coup ended the Brazilian democratic experience of the postwar period. In the transitional government that followed, anchored in an alliance between the military and the liberal right, emerged the first attempt to recognize the existence of systematic racial discrimination in the country and to implement affirmative action measures to correct it. This happened in November 1968, shortly before the military broke their liberal commitment and institutionalized an authoritarian military regime. Using mainly epochal documents, this paper analyzes the political conjuncture that allowed affirmative action to be proposed and its posterior rejection by the military, crystalizing "racial democracy" into the ideology and politics of the regime. It mainly analyzes the social forces that anchored the proposal of affirmative action, and those who reacted and aborted its discussion.

[1] Paper preparado para a Reunião

KEYWORDS: quotas, authoritarianism, liberalism, military regime.

da LASA em Puerto Rico, em maio de 2015. Essa reflexão está sendo desenvolvida no âmbito de um projeto do Centro de Estudos da Metrópole (Cebrap, USP), financiado pela FAPESP, Fundação de Amparo à Pesquisa do Estado de São Paulo, processo ${ }^{\circ}$ 2013/o7616-7. Agradeço aos colegas do CEM-Cepid pelos comentários à primeira versão do paper, discutido no Seminário Conjunto em 9 de março de 2015. Agradeço também a outros leitores de versões posteriores, como Marc Hertzman, Gustavo Rossi, Flávia Rios, Edilza Sotero, Matheus de Jesus e Irene Rosseto. Sou grato pelo apoio de Marilia Kuiumjian, na biblioteca da Universidade de Illinois, Urbana-Champaign, e de Edilza Sotero, na Biblioteca do Instituto de Estudos Brasileiros da Universidade de São Paulo.

Os militares que chegaram ao poder em 1964 por um golpe de Estado foram, no início, habilmente controlados por sua ala liberal e fortemente apoiados por políticos profissionais e setores da sociedade civil.Em 1968, esses militares procuravam, a todo custo, encontrar um caminho para dar continuidade a tal aventura e manter algumas insti- 
tuições democráticas ${ }^{2}$. O caminho não era fácil.As pressões vinham de todos os lados. Do Congresso, onde a oposição democrática procurava garantiro que restava do Estado de direito, enquanto a direita udenista buscava garantiro controle do governo; do movimento estudantil,que, apesar das baixas sofridas, se reorganizava rapidamente (Langland, 2013); do sindicalismo que, livre dos pelegos e ainda que expurgado dos comunistas, reorganizava as lutas por reposição salarial (Weffort, 1972); da extrema direita militar, que, através de atentados terroristas, procurava forçar um endurecimento do regime; e da extrema esquerda, que começava a ensaiar, através de ações armadas, a resistência ao novo regime (Ridenti, 2014).

Naquele momento, a coalizão militar-civil poderia reformar tudo - a lei de terras, as leis sindicais e trabalhistas, o sistema educacional, a política racial3 etc. - mas tinha, ao mesmo tempo, que vencer a resistência do passado, i.e., manter funcionando a antiga ordem e a organização social do país. Eram os limites entre a "revolução" e o "golpe de Estado" que estavam em jogo. Em outras palavras, assistia-se ao choque entre a tradição autoritária brasileira, que gerara a estrutura sindical e a democracia racial 4 , por um lado, e, por outro, o liberalismo udenista, que poderia sugerir novas soluções na política educacional (privatização do ensino superior), no mercado de trabalho (regulamentação e intermediação do trabalho) e na política racial. Foi nesse contexto que surgiu a primeira proposta de adoção de políticas de ações afirmativas para fazer face à discriminação racial no Brasil, que poderia no futuro se tornar um foco de tensão social e de desestabilização da política externa.

Vista do tempo presente, nada mais natural que tal proposta ter medrado nesse momento. Primeiro porque, um pouco antes, no início dos anos 1960, os Estados Unidos, referência obrigatória para a política brasileira, premidos por séria crise de legitimidade internacional e por crescentes e violentos conflitos raciais, adotara tais políticas; segundo, porque as ações afirmativas poderiam trilhar a tradição brasileira, inaugurada por Vargas com a lei de $2 / 3$ de reserva de vagas para os trabalhadores nacionais. Mas não foi assim que viram os contemporâneos desses acontecimentos. Tal proposta foi rapidamente abortada depois de renovadas loas à democracia racial, a qual deveria ser e permanecer a nossa única forma autêntica de política racial.

Neste texto, busco desvendar as forças que, naquela conjuntura, denunciaram a discriminação racial dos negros; o modo como parte da tecnocracia do Estado e autoridades reagiram a tais denúncias, que chegou mesmo a gerar uma incipiente proposta de ação afirmativa; e como a tradição intelectual dominante, reatualizando o imaginário nacional que via o Brazil como país mestiço, e evocando a eficácia de uma suposta legislação antirracista, abortou tal proposta.
[2] Ver, entre muitos, Ridenti (2014), que traça uma breve e correta trajetória do regime militar.
[3] Politica racial no sentido que lhe deu Wagley (1968, p. 164): "o processo de 'absorção' (Pierson) ou de 'embranquecimento' (Lynn Smith) do negro exprime a política profunda do Brasil em matéria racial".

[4] A doutrina da democracia racial, tal como formulada pelo Estado Novo (Gomes, 1999; Guimarães, 2012), era autoritária porque prescindia e diminuía a importância das instituições da democracia política liberal para a consecução da igualdade racial. 
[5] Jocélio Santos (2005) analisa tal episódio em sua tese de doutorado. Devo a ele, em 1998, o conhecimento desses fatos, e já tinha feito referência a esse episódio em meu livro Racismo e anti-racismo no Brasil, de 1999. A minha coleta de dados seguiu suas pistas. Jarbas Passarinho não deixou nenhuma referência escrita a esse episódio, seja em sua autobiografia, seja em seus artigos na imprensa brasileira. Tal fato não é documentado em sua biografia nem na literatura, acentuando-se as minhas referências e as de Jocélio.

[6] O Paulo César, branco, que assina a matéria era então, em 1968, um jovem repórter do $J B$, assim referido por Mauro Malin (2010): "Na reportagem havia uma garotada disposta. Paulo César(PC)Araújo, Fritz Utzeri, Ramaiana Vaz Vargens, Macedo Miranda (Macedinho, já falecido), Bella Stal, João Batista de Freitas, Tarcísio Baltar, Israel Tabak". Ricardo José Gonçalves Fontes postou o seguinte comentário sobre ele, no AlbumJotaBeniano, em 10 de setembro de 2010 , comentando a Foto 1: "Paulo César Araújo (PC), foi disparadamente o melhor repórter internacional (correspondente internacional), do jornalismo brasileiro. Exímio entrevistador, sempre com raciocínio rápido e com perguntas inteligentíssimas, colocando o entrevistado numa 'sinuca'. Dificilmente aparecerá outro do nível dele. Foi correspondente em Nova York e Londres na década de 80 pela Rede Globo. Morreu em um acidente de carro, na Lagoa Rodrigo de Freitas em 23/12/87".

\section{O EPISÓdI0 5}

Na edição de domingo, 3 de novembro de 1968, o Jornal do Brasil, então o mais importante dos jornais diários brasileiros, trouxe uma reportagem de página inteira, assinada por Paulo César de Araújo ${ }^{6}$, intitulada "Discriminação racial dificulta empregos", em que o autor relata, em estilo de jornalismo investigativo, as dificuldades dos "brasileiros de cor" para encontrar emprego na cidade do Rio de Janeiro.A chamada, na primeira página, era "Preconceito no trabalho", e no seu texto lia-se: "O racismo na atividade profissional deixou de ser um preconceito velado para se tornar um estrangulamento às pretensões dos candidatos de cor". Como se lê na matéria, aparecem de forma desordenada e confusa os três termos que marcarão, na discussão política das relações raciais no Brasil, a passagem dos anos 1960 para os anos 1970: preconceito, discriminação, racismo.

Paulo César Araújo (o último sentado à esquerda)

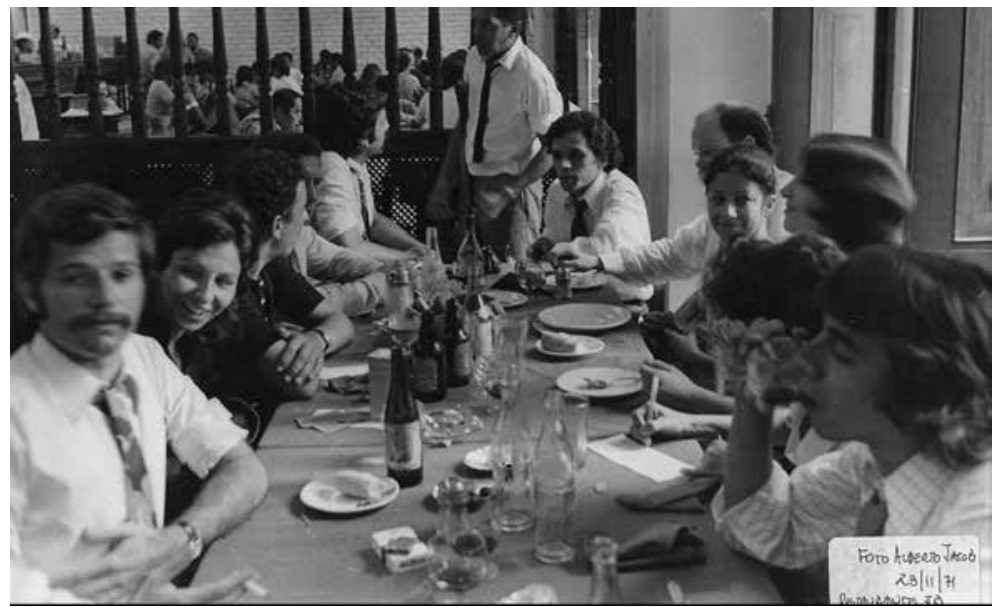

Fonte: foto publicada no AlbumJotaBeniano, em 5 de junho de 2010, com a seguinte legenda: "A foto de Alberto Jacob feita em 23 de novembro de 1971 no restaurante 'Britos' (notem a patuleia ao fundo no bandejão) é realmente an-to-ló-gi-ca! Vejam: Sergio Fleury, a Benoliel, Humberto Borges, nariz do Hélio Kaltman, Paulo César Araújo, Artur Pitombeira, Dácio Malta, a careca do Peter Matheson, Graça Monteiro, Diane Lisbona e Maurício 'Lacraia' Tavares. A mão assinando um pseudo cheque seria de quem ??? Postado por sergio FLEURY às 20:49".

A reportagem concentra-se em ouvir assistentes sociais de dois serviços oficiais de agenciamento de emprego, o Sopec (Serviço de Orientação Profissional e Colocação) do Banco da Previdência e o Serviço de Emprego da DRT (Delegacia Regional do Trabalho).Aimportância das qualificações raciais na colocação de trabalhadores de ambos os sexos é ressaltada insistentemente pelas assistentes sociais, entre os demais critérios discriminatórios, como idade, altura eeducação formal. E foi esse realce, considerado escandaloso, que o jornalista transpôs para a sua matéria. 
O coronel Jarbas Passarinho, uma das cabeças pensantes do regime, então titular do Ministério do Trabalho, às voltas com legitimare institucionalizar uma nova política trabalhista para o país, e respondendo a pressões salariais de diversas categorias sindicais e associativas, entre elas metalúrgicos e magistrados, responde imediatamente, na edição do dia 5 do mesmo jornal. A matéria desse dia dá conta de que, por telex urgente, de Brasília, o ministro exigira providências do DNMO (Departamento Nacional de Mão de Obra), lembrando que a Lei Afonso Arinos deveria ser acionada. Reconhecendo, entretanto, a dificuldade de aplicação daquela lei, o ministro determinara "estudos urgentes [...] porque pretende colocar o Ministério como obstáculo insuperável à discriminação racial" $(J B, 5 / 11 / 1968$, p.3).A mesma matéria adianta a reação de técnicos do departamento, sem citar nomes:

Segundo técnicos do Ministério do Trabalho e do Tribunal Superior do Trabalho, "uma lei semelhante à dos $2 / 3$ poderia solucionaro problema. [...] "Depois de uma pesquisapara estabelecerapercentagem da mão de obranegra no mercado de trabalho e destacados os ramos mais procurados por essa população, deveríamos partirpara umaleique regulasse oassunto" - revelou um técnico do Ministério do Trabalho. Essaleipoderiaestabelecer, porexemplo, que certas empresas seriam obrigadas a manter em seus quadros $20 \%$ de empregados de cor, algumas $15 \%$ e outras $10 \%$, conforme o ramo de suas atividades e respectivo percentual de demanda.

Na ediç̧ão seguinte, de 6 de novembro, o JB volta a noticiar possíveis soluções para a discriminação racial, inquirindo diversas instituições estatais. Por um lado, a Justiça do Trabalho parece descartar a solução legal:

Na Justiça do Trabalho, o fato é encarado como "problema do Executivo", pela ausência de provas concretas que, geralmente, envolvem a discriminação de fundo racial.

Por outro lado, parece haver resistências à adoção de medidas punitivas a empresas:

Segundo esse técnico, o DNMO acha que é mais conveniente continuar a estabelecer convênios com a iniciativa privada, aceitando a discriminação, do que encerrá-los - como uma forma de pressão - e prejudicar os que são beneficiados.

A crítica a essas soluções parece reforçar a reserva de vagas como a melhor saída, já que a reportagem termina com a seguinte argumentação técnica: 
Confrontada a oferta e a procura diária no emprego - através do controle das agências de colocação pública e privada - e analisadas as causas da ausência do homem de cor em certas atividades - o Ministério do Trabalho contará com elementos que podem solucionar o problema.

No dia 9 de novembro, respondendo a um repórter, depois de palestra pronunciada na Câmara Americana do Comércio, em Brasília, Passarinho nega que um projeto de "obrigatoriedade de admissão pelas empresas de pessoas negras" esteja sendo elaborado em seu ministério:

"Os jornais - afirmou - são muito poderosos no Brasil. Por isso, os jornais nunca mentem. Eles às vezes se equivocam. Eeste é um caso de equívoco. Não há nenhum projeto nesse sentido; só especulação."

A negativa do ministro, entretanto, não foi o ponto-final. Possivelmente, porque se acreditava que realmente algo nesse sentido estava sendo discutido no ministério. No dia seguinte, 10 de novembro, em editorial intitulado "Democracia racial", o Jornal do Brasil se manifestou contrário a leis de reserva de vagas; enquanto a escritora Rachel de Queiroz utilizou a sua coluna nos DiáriosAssociados para atacar veementemente iniciativas desse tipo. E assim se encerra o episódio. Seus argumentos, que analisaremos adiante, parecem reproduzir os parâmetros ideológicos que receberá a questão racial durante todo o regime militar.

Quem esteve por trás dessa iniciativa abortada? Jornalistas e técnicos do DNMO? Intelectuais e jornalistas negros? Diplomatas estrangeiros? Técnicos do DNMO e ativistas negros? O modo como transcorreram os fatos - uma reportagem-denúncia, seguida de declarações técnicas e minuciosas que apresentavam soluções completamente compatíveis com a tradição jurídico-trabalhista brasileira, de simples extensão da lei de $2 / 3$ - pode apontar para a hipótese de articulação de um tipo desses. Mas é também possível que técnicos do Ministério do Trabalho, e até mesmo o seu titular, numa conjuntura de ampliação dos conflitos raciais nos Estados Unidos e de possível ampliação da campanha de denúncias de discriminação racial no Brasil, estivessem sondando a reação da opinião pública a uma lei que abortasse tais problemas e, antecipando-se, desejassem ganhar o apoio da massa trabalhadora, em sua grande parte de cor, tal como Vargas o fizera. No entanto, a leitura atenta da matéria passa a impressão de que se tratava de uma reportagem regular, sem intenção prévia de averiguar racismo, que acabou por apresentar um achado para o repórter. Nesse caso, teriam sido as circunstâncias políticas do momento e não qualquer movimentação de um dado grupo de interesse que terão dado relevância e possibilitado o desdobramento da "descoberta".

Nos itens seguintes, exploro essas interpretações. 
Depois da guerra, no período de discussão da Constituinte de 1946, o tema do preconceito de cor e da discriminação dos negros, levantado no fim da Primeira República pela Frente Negra Brasileira, principalmente em São Paulo, voltara a ser mencionado constantemente por jornais7. Episódios como aqueles que tiveram lugar na rua Direita e na praça da Sé, em São Paulo, durante o footing de negros ${ }^{8}$, envolvendo polêmica interpretação de intelectuais e jornalistas, como Paulo Duarte (1947), José Lins do Rego (1947), Sergio Milliet (1947) e Rachel de Queiroz (1947), reavivaram a discussão sobre o preconceito de cor no Brasil, e estiveram na raiz dos primeiros estudos sociológicos sobre o assunto (Bastide e Fernandes, 1955). De fato, toda a discussão das ciências sociais brasileiras, em seus anos formativos, foi sobre a existência e as características do preconceito de cor no Brasil: seria apenas de cor, seria racial, haveria apenas preconceito e não discriminação9 ${ }^{9}$ seria apenas de classe? (Guimarães, 2012).

Do mesmo modo, desde os anos 1940, vários episódios de discriminação registrados em hotéis do Rio de Janeiro e de São Paulo, envolvendo principalmente afro-americanos em visita ao país, ganharam repercussão, seja na imprensa negra norte-americana (Hellwig, 1992; Francisco, 2014), seja no Brasil, e puseram sob suspeita a imagem de democracia racial, que já se tornava consensual, tanto internacional quanto nacionalmente (Guimarães, 2012). O último desses episódios, envolvendo a dançarina, antropóloga e ativista negra Katherine Dunham, tivera especial repercussão, dada a sua reação firme, causando grande mal-estar nacional, inclusive no Congresso, onde intelectuais como Gilberto Freyre e Afonso Arinos reagiram com veemência. A lei 1.390, sancionada por Getúlio Vargas em 3 de julho de 1951, conhecida como Lei Afonso Arinos, parece ter sido a resposta a esses episódios. Resposta que foi tida como adequada e definitiva, restabelecendo o status quo da nossa democracia racial. Em seu artigo $1^{\circ}$, rezava a lei: "Constitui contravenção penal, punida nos termos desta lei, a recusa, por parte de estabelecimento comercial ou de ensino de qualquer natureza, de hospedar, servir, atender ou receber cliente, comprador ou aluno, por preconceito de raça ou de cor".

Nos anos 1960, o famoso diário de Carolina de Jesus (1960) sobre a miséria em que vivia a população negra no Brasil e reportagens como o ensaio fotográfico de Gordon Parks (1961) para a Life Magazine foram também percebidos como desafios para a democracia e a paz racial no Brasil. Mais ainda, como sugere o título da referida reportagem da Life - "Pobreza: o temido inimigo da liberdade" -,em clima de Guerra Fria, era o "mundo livre" que estaria ameaçado pela pobreza e pelas discriminações sociais e raciais. Depois do golpe militar de 1964,
[7] Ver, entre outros, Guimarães e Macedo (2008); Sotero (2014).

[8] Sobre o episódio, ler o excelente artigo de Bastos (1988). Ver também Maio (1999).

[9] O "preconceito", tecnicamente, refere-se a atitudes e valores, e a "discriminação", a comportamentos efetivos. Na linguagem da época, "cor" referia-se a características somáticas, que variavam de indivíduo a indivíduo, enquanto "raça", a características físicas herdadas. 
[10] Note a confusão que Arinos promove, de um lado, entre "discriminação racial" e "preconceito de raça"; $\mathrm{e}$, do outro, entre "crime" e "contravenção penal". Apenas os últimos termos dos pares constam na Constituição. A confusão entre preconceito e discriminação, como veremos adiante, é constitutiva de um discurso ideológico e de uma política racial que ficou conhecida como democracia racial. ademais, uma nova onda de denúncias começou a ganhar corpo, com o alijamento da vida política de algumas proeminentes lideranças negras, como Abdias do Nascimento e Guerreiro Ramos, e a publicação da tese de titularidade de Florestan Fernandes (1965), intelectual bastante ligado aos meios negros de São Paulo, que procurava tematizar exatamente "o mito da democracia racial" brasileira.

Em carta aberta ao $1^{\circ}$ Festival de Artes Negras de Dacar, em 1966, do qual o Teatro Experimental do Negro fora excluído pelo governo brasileiro, Abdias do Nascimento (1966, p. 98) escrevia:

Nenhuma outra comunidade negra, fixada em país de civilização ocidental, talvez sofra de maneira tão trágica a pressão de um meio social só na aparência totalmente favorável. Pois desde o recôndito do seu procedimento, esse meio mantém vigilante e severa censura aos esforços de afirmação do negro e de sua tomada de consciência.

A resposta conservadora a essa nova onda de protestos negros, agora em fóruns internacionais, foi dada com a introdução na Constituição de 1967, outorgada pelo regime militar, da seguinte frase no parágrafo $1^{\circ}$ do seu artigo 150 : "Todos são iguais perante a lei, sem distinção de sexo, raça, trabalho, credo religioso e convicções políticas. $O$ preconceito de raça será punido pela lei" (itálico meu). Seu autor, o mesmo deputado Afonso Arinos, expressou assim o que considerava ser um ponto-final dado à questão:

De tudo o que pude fazer nos meus vinte anos de parlamento, de todas as lutas em que me empenhei durante esses quatro lustros, e que foram as lutas do meu tempo, talvez nada permaneça de duradouro, exceto aquele pequeno texto [a lei 1.39o], no qual, muito mais que a minha, falou sem dúvida, acima dos séculos, a voz memorável do meu povo. [...] no fim do meu mandato de senador, em janeiro do ano corrente [1967], [coloquei] no próprio texto da nova Constituição aquele dispositivo, que não encontra similar em qualquer outra Constituição nacional do mundo: "A discriminação racial será punida pela le $i^{\mathrm{i}}$ ". Hoje o preceito está claramente inscrito na lei magna, como expressão genuína do que já vinha, há tempo, no coração do nosso povo. (Arinos, 1967, p.46)

Pois bem, em outubro de 1967, a revista Realidade, que se destacava na imprensa brasileira com uma proposta totalmente nova de jornalismo investigativo e de opinião (Faro, 1998), dedica seu número 19 ao "Racismo: Estados Unidos e Brasil". Recordemos brevemente o contexto histórico daquela publicação, pois isso nos ajudará a situar a reportagem do $J B$ do ano seguinte.

No verão nórdico de 1967, em julho, os Estados Unidos tinham sido palco de uma das mais violentas revoltas raciais de sua história, 
com dezenas de bairros negros em chamas e confrontos policiais sanguinários. Lideranças pacifistas, como Martin Luther King, já vinham perdendo rapidamente espaço para líderes radicais, como Malcom X, e jovens líderes estudantis ou mulçumanos que clamavam por poder e não apenas por direitos civis. Organizações como a SNCC (Student National Coordinating Committee) e os Panteras Negras passavam ao proscênio com a palavra de ordem Black Power. Esses jovens, como Stokely Carmichael, do SNCC, procuravam também forjar alianças internacionais terceiro-mundistas, abraçando a teoria do colonialismo interno (Guimarães, 2014) e procurando se aproximar dos líderes anti-imperialistas da África, da Ásia e da América Latina. Foi nesse verão incendiário de 1967 que Fidel Castro organizou em Havana a primeira reunião da OLAS (Organization of Latin American Solidarity), e convidou Stokely Carmichael para representar o povo negro oprimido da América. Este, ecoando o chamado de Che Guevara na OSPAAAL (Organization of Solidarity of the People of Asia, Africa and Latin America) para que se criassem "um, dois, três, muitos Vietnãs", discursou:

Estamos [os jovens negros] caminhando para controlar nossas comunidades afro-americanas, assim como vocês estão se movendo para tomar o controle de seus países e de todo o continente latino-americano, das mãos de potências imperialistas estrangeiras. [...] O próximo Vietnã será neste continente, talvez na Bolivia, Guatemala, Brasil ou República Dominicana. (Reston, 1967)

Foi nesse contexto que a revista Realidade, sob a nova direção de Odylo Costa, filho, organizou esse número, buscando abrigá-lo sob o tema geral da fraternidade humana, com certeza para evitar que ele fosse censurado como fora o número 10, de janeiro de 1967, sobre a mulher brasileira. Dizia Odylo:

Nas páginas que seguem apresentamos duas reportagens sobre faces diversas do mesmo problema: o da antifraternidade. Numa, o jornalista conta o que viu, ouviue sabe sobre a discriminação racial nos Estados Unidos.Noutra, uma pequena equipe corre algumas capitais do Brasil para espiar como anda o preconceito de cor por estas bandas, testando as diferenças de reação em face de um branco e de um negro.

Além dessas duas reportagens, o número traz em encartes o texto da lei 1.390; uma nota demográfica sobre a população brasileira por cor, projetada para 1970; uma nota sobre a resolução da UNESCO sobre a inexistência cientificamente estabelecida de raças humanas; e três pequenos depoimentos - de Afonso Arinos, do médico negro 
Edgard Teotônio Santana e do diplomata Raimundo Souza Dantas, também negro. O editor avisa ainda que:

Tais foram as proporções que atingiu essa reportagem que não nos épossivel publicar neste número algumas contribuições a que atribuímos particular importância, entre elas o depoimento de um escritor ilustre, "branco da Bahia", que se inclui entre os negros e narra o que tem sido a luta deles em S. Paulo, Fernando Goes; e um ensaio do sociólogo Florestan Fernandes sobre preconceito e ascensão social. Anunciamos ao leitor essa colaboração especial para o prosseguimento do debate que abrimos.

Mas a Realidade nunca retomou o "debate".

Uma pequena análise desse número será proveitosa para a compreensão do fracasso da nossa primeira tentativa de estabelecer ações afirmativas no Brasil.

$\mathrm{Na}$ introdução ao número, Odylo Costa, filho, procura estabelecer com clareza o terreno ideológico e o objetivo da reportagem. Reforçando as crenças raciais vigentes, chama de discriminação racial a antifraternidade que flagela os Estados Unidos, e de preconceito de cor a antifraternidade flagrada no Brasil. Mas o tom não parece ser conciliador ou apaziguador em relação aos que negavam a existência do racismo no Brasil. Ainda que se note a preocupação do autor com evitar ser acusado de exagero ou oportunismo, parece que sua intenção é honesta em notar diferenças marcantes entre as realidades raciais nos Estados Unidos e no Brasil. Para emprestar objetividade às suas observações iniciais, ele se vale dos estudos da UNESCO e, principalmente, da distinção de Oracy Nogueira (1955) entre preconceito racial de marca e de origem. Em suas palavras:

Não há, entre nós, como nos Estados Unidos, exclusão ou segregação incondicional dos membros de grupo determinado, e sim preterição ou injustiça na luta individual. Lá os dois grupos se hostilizam como unidades sociais distintas. E isso não existe aqui. (Realidade, 1967, p. 23)

Essa comparação de nossas mazelas com males mais graves já indica em que terreno se coloca.

Seu objetivo, o que justifica moralmente a reportagem, retirando-lhe qualquer caráter de sensacionalismo, ou de oportunismo político, é justamente evitar que, pelo silêncio e pela negação, tal preconceito venha a se transformar em ódio racial: "o preconceito existe, cuidado com ele, para que não degenere em ódio, discriminação, segregação, conflito, violência" (Realidade, 1967, p. 23).

Assim se delineiam logo no começo alguns traços marcantes da nossa ideologia racial, mesmo quando professada pela esquerda 
progressista: o reconhecimento da discriminação racial andava a par da negação da legitimidade de um protesto negro que ganhasse contornos por demais políticos; o racismo era tratado como preconceito, seu caráter estrutural negado e tomado como manifestação de indivíduos. Enfim, o terreno autoritário da democracia racial parecia continuar trilhado pelas esquerdas, em que pese a sua desmistificação já em curso.

Esse traço característico pode ser descoberto se cotejarmos as duas reportagens.Aque cobre os Estados Unidos, assinada por Carlos Azeve$\mathrm{do}^{11}$, centra-seem sua experiência no Shaw, bairro negro de Washington, eentrevistas comlíderes do SNCC ecitações de ativistas do CORE(Congress for Racial Equality). Azevedo conta didaticamente como ocorreu a grande imigração dos negros para as cidades do norte e do meio-oeste americano, entremeando em seu relato estatísticas sobre as desigualdades raciais norte-americanas e momentânea falência da via pacifista de Luther King e dos governos democratas. Volta e meia, no texto, aparece o motivo por que sua presença no bairro e nas entrevistas foi tolerada pelos ativistas radicais negros: um brasileiro seria um "não branco". A narrativa viva da experiência de uma noite no Shaw, na esquina da rua 14 com a U, presenciando a chegada de viaturas policiais para prender um adolescente negro, sendo hostilizado por um drogado que o chamou de honky, não foi suficiente para caracterizar o racismo americano para o público brasileiro. Escreve Azevedo:

Em Washington fui apresentado pessoalmente ao racismo. Foi numa noite em que eu e cinco universitários brasileiros conversamos com um universitário negro norte-americano, no saguão do hotel onde estávamos hospedados. Depois de exigir do funcionário da portaria que o negro se retirasse, umvelho, branco e aparentemente meio bêbado, nos perguntou: "O que estou vendo é um sonho ou fiquei louco? O que faz um negro entre vocês?".

A reportagem, que cobre seis cidades brasileiras - Belém, Recife, Salvador, Rio de Janeiro, São Paulo e Porto Alegre - é assinada por Narciso Kalili12 ${ }^{12}$, branco, e Odacir de Mattos ${ }^{13}$, negro, com fotos de Luigi Mamprine Geraldo Mori, e intitula-se "Existe preconceito de cor no Brasil".A reportagem pretendia flagraro preconceito e a discriminação raciais no Brasil através de vários testes, realizados pelos dois jornalistas, com a ajuda de colaboradoras recrutadas localmente, situações documentadas fotograficamente, de atitudes em relação a casais inter-raciais, hospedagem em hotéis, procura de moradia, atendimento em ambulatórios médicos, matrícula em escolas e de urgência médica, na rua, todas forjadas pelos dois jornalistas. Ao contrário da reportagem feita nos Estados Unidos, não há, em todo o texto, nenhum dado estatístico que documente desigualdades raciais. O foco centra-se em
[11] "Carlos Alberto de Azevedo nasceu em 11 de dezembro de 1939, em São Paulo. Jornalista desde 1959, foi repórter em A Hora, O Estado de São Paulo, Folha de S.Paulo, Diário da Noite, nas revistas O Cruzeiro, Quatro Rodas, entre outros veículos até 1968. Nesse período, participou da fundação da revista Realidade, que inspirou toda uma geração de jornalistas independentes na promoção dos direitos humanos e da cultura brasileira. Em seguida, participou do movimento de resistência à ditadura militar, colaborando em jornais clandestinos como Libertação e Classe operária e em livros clandestinos como o Livro Negro da Ditadura Militar (1970) e Politica de genocídio contra os índios do Brasil (1973). Perseguido pelos órgãos de repressão, viveu cerca de dez anos na clandestinidade (1969-1979). Entre 1975 e 1979 foi colaborador do jornal Movimento, mantido e produzido por jornalistas (sem patrão). Após a anistia trabalhou na TV: no Globo Rural (TV Globo), 1981-85; na TV Cultura (1986-87). Fez programas políticos de TV para o PCdoB entre 1989-98. Também continuou a militar na imprensa independente escrevendo nas revistas Caros Amigos e Retrato do Brasil. Foi editor-chefe das campanhas de TV de Lula à Presidência da República em 1989 e 1994. Entre outros, escreveu os livros Do tear ao computador, a luta pela industrialização no Brasil (três edições, 1986/88/89, com Guerino Zago Jr.) e Cicatriz de reportagem (2007), publicado pela Editora Papagaio, reunindo suas melhores reportagens. Participou como editor-chefe da elaboração dos livros Brasil, direitos humanos (2008); eHabeas corpus-que se apresente o corpo (2010), ambos para a Secretaria de Direitos Humanos da Presidência da República. O livro Jornal Movimento, uma reportagem é seu trabalho mais conhecido, escrito com a colaboração de outros autores, sob encomenda da 
Editora Manifesto." Texto copiado de http://www.portaldosjornalistas. com.br/perfil.aspx?id=13529. Ver foto no anexo.

[12] Segundo depoimento de Mylton Severiano da Silva (http://doclondrina.blogspot.com.br/2012/06/ homens-do-panorama-narciso-kalili-e.html): "Narciso caiu fora de Realidade, meses antes que a equipe inicial se desfizesse. Foi fazer jornalismo diário na Última Hora, já dos Frias mas ainda combativa. Narciso era o editor-chefe, creio, mas ia às ruas cobrir as passeatas e protestos e acabava se juntando aos 'subversivos', gritando slogans contra a ditadura e acolhendo perseguidos (coisa que vários de nós fizemos, inclusive eu, sob risco até de morte)". Narciso foi preso em 1974, pela Operação Bandeirantes, por conta de uma reportagem sobre o Watergate (Nitrini). Quando solto, perdeu o emprego que tinha na TV Cultura e recomeçou a vida jornalística em Londrina, PR. De volta a São Paulo, foi editor dos noticiários da Rádio Jovem Pan. Morreu em 1992.

[13] Odacir de Mattos trabalhou em diversos jornais na capital paulista como revisor e foi também ativista negro, membro fundador da Associação Cultural do Negro, em São Paulo, e do Jornegro, na mesma cidade. Dirigiu o Centro de Cultura e Arte Negra (Cecan) a partir de 1974. Foi ligado também aos jovens jornalistas socialistas do Versus, principalmente a Thereza Santos (Silva, 2011:284; Rios, 2014). atitudes e comportamentos observados. O resultado pode ser sintetizado assim: forte recusa a casais inter-raciais; nenhuma solidariedade com negros em situação de urgência médica; uma pletora de manifestações verbais de preconceito, mas nenhuma ou quase nula desigualdade de tratamento na procura de escola; alguma discriminação, ainda que não radical, sempre dissimulada, na procura de moradia ou hospedagem em hotel. Maior disposição dos jovens negros que dos adultos em falar da discriminação que sofriam, negação generalizada da existência de preconceito entre os brancos. Pouca diferença entre cidades, ainda que em Porto Alegre a tensão racial parecesse maior.

O que realmente chamou minha atenção, repito, foi que a preocupação dos repórteres esteve voltada primordialmente para flagrar atitudes e valores, assim como diferenças de tratamento. Não houve preocupação alguma com estatísticas de desigualdades estruturais. Mas algo parecia já mudar nessa postura de excessivo foco em atitudes e valores e total descaso com a situação de desigualdade racial em que vivia o negro brasileiro. Essa mudança pode ser sintetizada num comentário de Odacir de Mattos a Kalili, que lhe conta a rejeição preconceituosa que ouvira de uma prostituta branca, numa das sessões do experimento que fizeram. Vale destacar a nova ideologia que transparece nas palavras do jornalista:

Sentimentalmente, o preconceito não me afeta. Acho que o branco tem todo o direito de não gostar de mim como pessoa. Assim como eu tenho o direito de não gostar dele. Não vou, por isso, me incomodar com as opiniões de uma prostituta que pode não querer dormir com um negro, nem com o fato de o dono de um hotel ou boate barrar minha entrada. Tenho de desenvolver minha luta num plano mais elevado. O preconceito e a discriminação prejudicam minha vida cultural, familiar, e sinto que devo lutar. Mas não com as manifestações do preconceito, e sim contra as causas que the deram origem. Eu não me sinto humilhado por opiniões como a desta mulher. Mas isto junto a todos os outros tipos de discriminação limita a vida de um negro a um nível bastante baixo, do qual ele dificilmente pode sair. (Os destaques são meus.)

Era o repúdio a tratar o racismo como manifestações individuais de preconceito, ou mesmo de discriminação, para pensá-lo como limitações estruturais ao desenvolvimento pessoal e coletivo dos negros, que já estava em gestação nos anos 1960 no Brasil. Esse processo, entretanto, só estará completo mais tarde, quando dois novos elementos foram incorporados: primeiro, a demonstração científica, para efeito de convencimento, de que as desigualdades sociais e econômicas entre brancos e negros, no Brasil, eram de fato raciais, ou seja, consequência de discriminações, e não uma associação espúria entre classe e raça; segundo, a organização de movimentos sociais fortes que pressionassem 
por políticas antidiscriminatórias de cunho estrutural. A primeira condição começou a se desenvolver apenas no decorrer dos anos 1980, a segunda, em meados dos 1990 .

\section{A DENÚNCIA DO JB EM 1968}

A reportagem de Paulo César Araújo de 3 de novembro de 1968 tem, entretanto, duas singularidades importantes. A primeira, tratar exclusivamente de discriminações no mercado de trabalho, mais especificamente na colocação deempregados recrutados por agências deemprego; a segunda, serem essas agências governamentais ligadas ao Ministério do Trabalho. O seu assunto era excessivamente técnico, em que pesem o apelo popular e a linguagem acessível da matéria jornalística. Os entrevistados são técnicos do Departamento Nacional de Mão de Obra (DNMO) eassistentes sociais ligadas às duas agências públicas de colocação de mão de obra. É importante lembrar que o próprio DNMO fora criado recentemente pelo governo militar ${ }^{14}$ no bojo de uma completa reforma trabalhista e sindical, ainda em curso no momento da reportagem, que procurava reorientar o sindicalismo brasileiro e garantir maior produtividade do trabalho. Informa-nos a Sylvia Ely (1984, p. 267) que "O DNMO, efetivamente, começou sua atuação em 1967 e passou a atuar de modo muito similar ao do PIPMOI, ou seja, desenvolvendo recursos para queempresas, organizações sociais, pudessem implementarcursos de formação de mão de obra".

A primeira dessas características, apontar para problemas estruturais de geração de desigualdades entre brancos e negros, poderia sugerir algum envolvimento com ativistas, seja de esquerda, seja de organizações negras, interessados em propor ou pautar a reportagem. Os rápidos perfis que traçamos dos jornalistas que escreveram as reportagens mostram, entretanto, que, se Kalili e Mattos tinham ligações próximas com movimentos sociais, esse não parece ter sido o caso de Araújo. Ao contrário, o fato de ter sido, anos depois, escolhido pelo JB para cobrir o enterro de Pablo Neruda, no Chile, é indicativo de que não tivesse um passado suspeito aos órgãos de segurança $a^{15}$. A segunda característica sugere um roteiro diferente: teriam técnicos do DNMO interesse não apenas em problematizar a discriminação racial, mas também em torná-la um assunto de opinião pública? Não podemos averiguar essa possibilidade através de consulta aos arquivos do Ministério do Trabalho, mas ela é bastante plausível. O que a torna mais atraente é que os técnicos entrevistados não apenas revelam o problema, mas apontam para a sua solução de modo detalhado, a qual implica na consolidação do papel da DNMO na regulação do mercado de trabalho, ou seja, no que toca a relação de intermediação. Note-se que a reportagem generaliza para o mercado de trabalho a
[14] "Lei no 4.923, de 23 de dezembro de 1965 . Art. $7^{\circ}-\mathrm{O}$ atual Departamento Nacional de Emprego e Salário, do Ministério do Trabalho e Previdência Social, criado pelo art. $2^{\circ}$ da Lei $n^{\circ} 4.589$, de 11 de dezembro de 1964 , fica desdobrado em Departamento Nacional de Mão-de-Obra (DNMO) e Departamento Nacional de Salário(DNS)."

[15] As fotos de Neruda, registradas por Evandro Teixeira durante a reportagem de Paulo César, são as únicas a documentar realmente a autópsia e o enterro de Pablo Neruda (Fullgraf, 2013). 
[16] Kent parece ter sido um jornalista bastante ativo na cobertura de atentados aos direitos humanos na América Latina, cobrindo o massacre de estudantes em Tlatelolco, no México, em 1968, e também conflitos camponeses e indígenas naquele país. Sobre o Brasil escreveu pelos menos duas outras reportagens, em 1968, sempre no Los Angeles Times, sobre conflitos indígenas. Passou depois a assinar artigos na importante revista semanal de esquerda The Nation.

[17] A tese de doutorado de Kosling (2007) nos fornece evidências sobre a importância que o DEOPS emprestava à movimentação negra nos Estados Unidos. discriminação observada nas agências de intermediação, recentemente regulamentadas.

Mas há outro fato intrigante. Já no dia 10 de novembro o Los Angeles Times, em artigo assinado por Francis B. Kent ${ }^{16}$, do seu corpo editorial, faz a repercussão da reportagem do $J B$ e de seus desdobramentos com o título "Discriminação racial emerge no Brasil" e o subtítulo "O problema é reconhecido abertamente ao menos em jornal; ação governamental em curso". Essa rápida repercussão mostra que o tema era preocupação não apenas de ativistas, mas do público norte-americano e das autoridades brasileiras e norte-americanas. Estávamos no contexto da Guerra Fria, e o ativismo negro nos Estados Unidos parecia sair do controle, com algumas faç̧ões aliando-se a Fidel Castro, que por sua vez tinha presença cada vez maior nas lutas de libertação da África e na resistência armada aos regimes de direita da América Latina. Muitos liberais e conservadores, nos Estados Unidos e no Brasil, pareciam realmente enxergar no Brasil um grande problema negro em potencial ${ }^{17}$.

Tal contexto histórico serviria certamente para que vários possíveis atores e grupos enxergassem a oportunidade de avançar seus interesses nessa conjuntura. Para alguns, tratava-se de quebrar barreiras institucionais que limitavam as oportunidades de vida dos negros brasileiros. Nessecaso, podemos supor, apenas à guisa de exemplo, queo intelectual negro Guerreiro Ramos, exilado na Califórnia desde 1966 e ensinando na Universidade do Sul da Califórnia, pudesse ter algum contato com Kent. Mas é também crível que jovens economistas, diplomatas americanos, e mesmo intelectuais brasileiros em sintonia com o pensamento liberal que, nos Estados Unidos, forjava as affirmative actions, também tivessem interesse em que o governo militar brasileiro procurasse prevenir que o descontentamento negro se alastrasse no Brasil, tomando medidas de relocação de oportunidades compatíveis com a ordem liberal. Como governo de exceção, os militares poderiam impor tais políticas de ação afirmativa. Pode-se presumir que, se elas não chegaram a ser propostas, foi porque não havia condições políticas para tal, assim como, de fato, também não havia para outras políticas "liberais", tais como o fim do monopólio do petróleo, ou o controle da natalidade, que foram sugeridas pelo poderoso ministro do Planejamento, Roberto Campos, ao estafe militar(Rodrigues, 2001).

Sejam quais forem as cadeias de ação, o fato é que o ministro Jarbas Passarinho em nenhum momento se manifestou abertamente favorável a medidas de ação afirmativa, deixando que seus técnicos estudassem soluções, e, quando pressionado diretamente, lembrou que "os jornais são muito poderosos no Brasil", frase polissêmica, sendo um dos seus sentidos o de que o $J B$ teria sido usado para fazer pressão por ações afirmativas. 
O editorial do JB de 10 de novembro, "Democracia racial", procura não deixar dúvidas sobre a posição do jornal. Ancorado na já antiga tradição intelectual brasileira do nosso excepcionalismo e da nossa singularidade racial mestiça, o editorialista finca-se nesses dois argumentos: a nossa mestiçagem faria de discriminações raciais uma tolice - "A própria variedade dos termos designativos rescdo infinito espectro de cor da pele dos brasileiros demonstra a rica tessitura de uma raça que se forja na base de todas as raças e todos os sangues"; $\mathrm{e}$ havia o risco de institucionalizar o preconceito existente - "Seria um erro funesto impor qualquer paridade de brancos e gente de cor em escritórios. Isso constituiria uma cristalização do preconceito. Devemos punir esses tolos que discriminam sem criar estatutos que firmem a discriminação." A solução para esses casos, portanto, já estava dada na nossa lei e na nossa Constituição: "E o remédio é a aplicação severa da lei que pune os delitos de discriminação racial".

Rachel de Queiroz, em sua "Carta aberta ao ministro Jarbas Passarinho", repete os mesmos argumentos com mais veemência e argumentação mais detalhada, e invoca a mesma solução: "No Brasil, graças à sábia e benemérita Lei Afonso Arinos toda espécie de discriminação racial é considerada crime, sujeito a sanção penal". No caso, ações afirmativas seriam ainda piores que o crime de racismo: "E eu digo mais: é preferível que continue a haver discriminação encoberta e ilegal, mesmo em larga escala, do que vê-la reconhecida oficialmente pelo governo - já que qualquer regulamentação importaria num reconhecimento". A escritora, talvez assustada com o poder que o governo militar teria para impor tais medidas, chega mesmo a pedir que tal poder seja exercido pelo Serviço Nacional de Informações para punir os infratores da Lei Afonso Arinos.

Essa ideologia de democracia racial, que fique claro, não se baseia em valores universais, como liberdade individual e igualdade de oportunidades, mas, ao contrário, tem seu ponto de sustentação no imaginário nacional sobre a origem singular e mestiça do povo brasileiro, pensado como uma meta-raça à maneira de José Vasconcelos e Gilberto Freyre ${ }^{18}$. Seu autoritarismo está em se mover apenas sobre valores e atitudes que devem ser necessariamente comunitários, fechando-se completamente a qualquer realidade estatística ou de desigualdade estrutural de poder, que requeira a proteção de indivíduos pertencentes a grupos sociais específicos. Por isso, a mesma Rachel de Queiroz que, em 1947, atacava alguns intelectuais paulistas que negavam a existência da discriminação racial no Brasil se voltava em 1967 contra aqueles que pensavam em corrigi-la através de seu reconhecimento institucional ${ }^{19}$.

Mas haveria mesmo entre a intelectualidade e os políticos brasileiros uma corrente, ainda que pouco expressiva, de defesa dessa solução liberal ao problema da cristalização das desigualdades raciais?
[18] Tal ideologia se contrapôs tanto ao racismo científico de um Nina Rodrigues (1932), quanto à concepção de um São Paulo branco (Weinstein, 2006). Esta, no pós-guerra, foi atualizada pela referida polêmica entre modernistas paulistas e nordestinos; Sérgio Millet (1947, p. 7), por exemplo, escreveu: "Até às vésperas da grande imigração [europeia] a famosa fórmula de Martius, de um povo formado por três raças, o índio, o negro e o português, foi perfeitamente satisfatória. Desde a imigração, porém, essa fórmula deixou de significar um fato científico em relação aos estados do Sul e, em especial, a São Paulo".

[19] Aqui, é importante lembrar que, em 1947, tanto aqueles que negavam como os que reconheciam a existência do racismo, tanto os paulistas quanto os nordestinos, eram unânimes em condenar a existência de organizações negras, dos seus arrazoados e de suas reivindicações. Dizia Queiroz: "E comete o brilhante cronista um erro elementar quando atribui aos 'sociólogos de pacotilha', aos 'filósofos da mulataria', a fundação de ligas de homens de cor, de frentes negras, etc. Os filósofos da mulataria desejam justamente o contrário: acabar com essas ligas, com essas associações, entregar amplamente a população de cor na comunhão nacional, e acabar com quaisquer restrições que separam brancos de negros" (Queiroz, 1947, p. 2). Enquanto Rego (1947) lembrava que "nada tem a ver Gilberto Freyre com a tal sociologia 'negroide' que anda por aí". 
[20] O senador José Sarney (PMDB/ AP) apresentou, em dezembro 1999 , o projeto de lei ${ }^{\circ} 650$, que instituía cotas de ação afirmativa para a população negra no acesso aos cargos e empregos públicos, à educação superior e aos contratos do Fundo de Financiamento ao Estudante do Ensino Superior(FIES).
É fato que sustentáculos políticos do regime militar, como Marcos Maciel (2001) e José Sarney ${ }^{20}$, acolheram melhor, na nova conjuntura dos anos 1990, as demandas por ações afirmativas que os intelectuais tradicionais ou de esquerda, mas seu posicionamento naquela conjuntura dos anos 1960 precisa ainda ser averiguado. É também um fato que baluartes do pensamento liberal no Brasil, como Afonso Arinos (1967, p. 186), nunca foram muito apegados ao argumento da mestiçagem como diluidor dos conflitos raciais, preferindo realçar "nossa tradição católica muito mais integracionista" e aceitando que "o problema negro pode se agravar em nosso país; mas em consequência do problema geral do desenvolvimento econômico". Homens como Arinos não tinham pejo em falar abertamente em raças, ainda que ele ressaltasse que "são muito diferentes as condições de coexistência das raças branca e negra nos Estados Unidos e no Brasil".

\section{DISCUSSÃo}

Ainda que nossa pesquisa não possa aceitar em definitivo nenhuma das hipóteses interpretativas aventadas, as evidências reunidas parecem favorecer algumas em detrimento de outras.

Parece fora de dúvida que não houve motivação política de esquerda para pautar a reportagem do Jornal do Brasil, ainda que inegavelmente seu teor interessasse a ativistas negros, o que fica claro quando um jornalista estrangeiro "de esquerda" faz a repercussão da reportagem nos Estados Unidos.

Embora não tenhamos informações sobre quem eram os técnicos do DNMO e de suas ligações com o movimento negro brasileiro, podemos nos indagar se a proposta de cotas já aparecia na pauta do movimento àquela época. E a resposta é negativa.

Os três primeiros itens do Manifesto da Convenção Nacional do Negro (Quadro 1), de 1946, por exemplo, contêm reivindicações que foram atendidas plenamente pela Lei Afonso Arinos, de 1951. Coerentemente, a Declaração do I Congresso do Negro Brasileiro (Quadro 2), em 1953, não traz nenhuma reivindicação de política afirmativa. A reivindicação desse tipo que aparece com força, em 1946, se refere à política na área educacional, não ao mercado de trabalho. Dizia a quarta reivindicação daquele manifesto:

Enquanto não for tornado gratuito o ensino de todos os graus, sejam admitidos brasileiros negros como pensionistas do Estado, em todos os estabelecimentos particulares e oficiais de ensino secundário e superior do país, inclusive nos estabelecimentos militares. (Diário Trabalhista, 15/1/1947)

É bem verdade que já existiam demandas anteriores da Frente Negra Brasileira por dessegregação da Força Pública de São Paulo, das 
Forças Armadas e do Itamaraty. E que a luta por extensão dos direitos trabalhistas às domésticas era bandeira da plataforma político- eleitoral de candidatos negros como Abdias, em 1946. Ainda assim, a demanda por ações afirmativas no mercado de trabalho, no universo do ativismo negro, era coisa muito nova em 1968. Pouco provável, portanto, que sua sugestão nascesse de uma articulação de técnicos do DNMO com ativistas negros.

Em contrapartida, vale lembrar que começava a emergir no movimento negro, desde o pós-guerra, uma nova concepção de racismo, cuja ênfase nas oportunidades devida fazia com que se ressaltassem as consequências advindas das limitações impostas pela discriminação (Guimarães e Macedo, 2008). Problemas decorrentes da situação de pobreza e de privação já eram realçados no diagnóstico, e sua solução poderia estar seja em outro sistema econômico, que abolisse as classes, como a fala de Odacir de Mattos que transcrevi anteriormente parece sugerir, seja na forma de ações afirmativas que reequilibrassem as oportunidades de vida, como sugerido pelos técnicos do DNMO.

Os tecnocratas entrevistados pelo $J B$ se inclinavam claramente pela adoção de cotas e não de outras ações afirmativas e invocavam a política trabalhista de Vargas como exemplo de política compensatória bem-sucedida. Também é fato que tais técnicos estavam em contato estreito com o ministro do Trabalho, de perfil nacionalista e autoritário. Este, apesar de suas negativas quanto a estudos que estivessem em curso sobre a implementação de cotas, fora quem demandara "por telex urgente de Brasília" estudos para frear a discriminação racial no mercado de trabalho que fossem mais efetivos que a Lei Afonso Arinos. O timing da reportagem, das respostas dos atores envolvidos e das soluções aventadas parece dar credibilidade à versão de que se tratava de uma pauta articulada com os interesses do Ministério do Trabalho, estivessem ou não esses técnicos articulados com o seu ministro.

Não se pode, obviamente, descartar a possibilidade de que a cadeia de eventos tenha sido casual e que sua aparente causalidade se deva apenas às circunstâncias históricas favoráveis: perigo de que a agenda negra americana contaminasse os ativistas brasileiros, perigo de que tal agenda favorecesse a articulação internacional cubana, necessidade de responder à rearticulação do movimento operário brasileiro.

Quanto à ideologia que guiava os atores, parece também claro que o nacionalismo autoritário que conquistara porção significativa dos militares brasileiros, assim como de tecnocratas, tanto quanto o liberalismo político brasileiro, que também nunca escondeu seu viés autoritário, aparece nos seus argumentos. Em Jarbas, democracia e autoritarismo são valores que convivem. $O$ episódio da sugestão das cotas, que aqui relatamos, não é referido em suas memórias (Passarinho, 1996). Na verdade, aparece como silêncio, como um não evento: 
um fato sem desdobramentos políticos. Ao contrário, transparece nas memórias uma atitude que se coaduna com a noção de democracia racial, expressando a singularidade de nossa civilização no Ocidente - sermos autoritários em termos políticos e interpessoais, mas igualitaristas e tolerantes à mistura em termos raciais. Era, pois, uma relativização particular da ideia de democracia moderna. Podemos ler nas memórias de Jarbas referentes aos anos 1969, quando o regime militar enfrentava resistências à sua legitimidade em fóruns internacionais:

Sabendo o sr. Meany em sala próxima, dirigindo o encontro com as lideranças sindicais estrangeiras convidadas por ele, para reunião paralela, disse que não aceitava, sob nenhuma explicação, a grosseria que houvera. Ademais - continuei - não receberia lição de democracia de ninguém. Seria - perguntei-uma democracia perfeita aquela que garante direitos civis para uns e nega a outros; que emudece a voz de negros tirando-Ihes a vida (Martin Luther King fora assassinado em abril de 1968); que mantém em guetos populações discriminadas pela cor; $[. .$.$] Quem se arroga o direito de$ censurar há que prevenir-se contra o risco de ver cair sobre seu telhado as pedras que atirou no do vizinho. (Passarinho, 1966, p.360)

É um fato, entretanto, que liberais como Afonso Arinos, assim como o establishment jornalístico e os intelectuais modernistas, ainda apostavam todas as suas fichas, em 1968, em que a lei 1.390 e a Constituição de 1967 resolveriam a questão negra no Brasil. E o que realmente prevaleceu foi um entendimento bastante arcaico, e ultrapassado já naquela conjuntura internacional, de que se preveniria o acirramento da questão racial a partir de dispositivos legais e constitucionais que reiterassem o respeito à liberdade e a responsabilidade individual, coibindo e punindo o preconceito racial.Em termos doutrinários, esteera concebido como a causa da discriminação e essa última, como a causa das desigualdades. A confusão entre preconceito e discriminação era apenas uma questão de economia de palavras, pois o preconceito seria a sua causa última e matriz. Tal doutrina podia, ademais, conviver com a negação do racismo, ainda que se aceitasse a emergência ocasional de discriminações raciais, e conviver até mesmo com a aceitação do tratamento diferencial por classes, que seria considerado sistêmico no Brasil.

A verdade é que a concepção atual do racismo como um sistema de dominação colonial, coexistente, funcional, mas independente do sistema de economia capitalista, existia, naquela época, apenas entre os jovens ativistas negros do Black Power, podendo ou não estar ligada a anticapitalismo. Nos Estados Unidos, esse entendimento foi contra-arrestado pela política liberal, em muitos estados e municípios, que implementou ações afirmativas, protegendo a igualdade de 
oportunidades de vida, e multiculturais, que garantiam a autonomia da identidade cultural negra. No Brasil, a influência do Black Power se disseminará paulatinamente, a partir de 1969, nos meios negros e ganhará a cena pública pela sua repercussão na vida cultural do negro brasileiro nos centros urbanos, primeiro no Rio e em São Paulo, avançando depois para outras cidades, como Salvador e São Luis, através de movimentos como o funk, o Black Rio, o reggae, que envolviam mudanças de atitudes e comportamento, expressos em nova linguagem, vestuário, cortes de cabelo etc. A influência cultural negra americana será, portanto, a porta de entrada para que reivindicações de reconhecimento cultural pavimentassem reivindicações políticas no final do século XX ${ }^{21}$.

De todas as hipóteses, a que fica mais difícil de descartar, portanto, com o conhecimento que temos hoje, é a de que a sugestão de estabelecer cotas raciais para os trabalhadores colocados em empresas priva-

[21] A primeira delas de que tenho notícia, sem contar a protorreivindicação de 1947, foi um projeto de lei do então senador Abdias do Nascimento, em 1997 . das pelas agências de colocação estatais tenha sido uma iniciativa dos próprios técnicos do $\mathrm{DNMO}$, motivada provavelmente pelo desejo de fortalecer a importância do próprio departamento. Que tal desejo tenha sido veiculado pela grande imprensa e tenha permanecido em sua pauta por uma semana, entretanto, nos indica que havia alguma expectativa de que tal proposta pudesse encontrar respaldo em alguns grupos sociais e governamentais, naquele contexto de reformas trabalhistas dos anos 1960.

\section{QUADRO I}

MANIFESTO DA CONVENÇÃO NACIONAL DO NEGRO

1. Que se torne explícita na Constituição de nosso país a referência a origem étnica do povo brasileiro, constituído das três raças fundamentais: a indígena, a negra e branca.

2. Que torne matéria de lei, na forma de crime de lesa-pátria, o preconceito de raça.

3. Que orne matéria de lei penal o crime praticado nas bases do preceito acima, tanto nas sociedades civis e nas instituições de ordem pública e particular.

4. Enquanto não for tornado gratuito o ensino de todos os graus, sejam admitidos brasileiros negros como pensionistas do Estado, em todos os estabelecimentos particulares e oficiais de ensino secundário e superior do país, inclusive nos estabelecimentos militares.

5. Isenção de impostos e taxas, tanto federais como estaduais e municipais, a todos os brasileiros que desejarem se estabelecer com qualquer ramo comercial, industrial e agrícola, com capital não superior a $\mathrm{Cr} \$ 20.000,00$.

6. Considerar como problema urgente a adoção de medidas governamentais visando a elevação do nível econômico, cultural e social dos brasileiros. 
QUADRO 2

DECLARAÇÃO DO I CONGRESSO DO NEGRO BRASILEIRO

O Congresso recomenda, especialmente,

a) O estímulo ao estudo das reminiscências africanas no país bem como dos meios de remoção das dificuldades dos brasileiros de cor e a formação de institutos de pesquisas, públicos e particulares, com este objetivo;

b) A defesa vigilante da sadia tradição nacional de igualdade entre os grupos que constituem a nossa população;

c) A utilização de meios indiretos de reeducação e de desrecalcamento em massa e de transformação de atitudes, tais como o teatro, o cinema, a literatura, e outras artes, os concursos de beleza, e técnicas de sociatria;

d) A realização periódica de congressos culturais e científicos de âmbito internacional, nacional e regional;

e) A inclusão de homens de cor nas listas de candidatos das agremiações partidárias, a fim de desenvolver a sua capacidade política e formar líderes esclarecidos, que possam traduzir, em formas ajustadas às tradições nacionais, as reivindicações das massas de cor;

f) A cooperação do governo, através de medidas eficazes, contra os restos de discriminação de cor ainda existentes em algumas repartições oficiais;

g) O estudo, pela Unesco, das tentativas bem-sucedidas de solução efetiva dos problemas de relações de raças, com o objetivo de prestigiá-las e recomendá-las aos países em que tais problemas existem;

h) A realização, pela Unesco, de um congresso internacional de relações de raças, em data tão próxima quanto possível.

O Congresso condena, veementemente, considerando ameaças à tranquilidade da família brasileira:

a) A exploração política da discriminação da cor;

b) As associações de cidadãos brancos ou negros organizadas sob o critério do exclusivismo racial;

c) O messianismo racial e a proclamação da raça como critério de ação ou como fator de superioridade ou inferioridade física, intelectual ou moral entre os homens;

d) Os processos violentos de tratamento dos problemas suscitados pelas relações interétnicas.

Nascimento, Abdias (org.). O negro revoltado. Rio de Janeiro: Editora Nova Fronteira, 1982, $2^{\mathrm{a}}$ edição.

\section{REFERÊNCIAS BIBLIOGRÁFICAS}

Arinos, Afonso. "As origens da lei no coração do nosso povo". Realidade, no 19 , outubro, 1967, p. 46. . Realidade, $\mathrm{n}^{\circ} 19$, outubro, $1967, \mathrm{p} .186$.

Bastide, R., e Fernandes, F. Relações raciais entre negros e brancos em São Paulo. São Paulo:Anhembi, 1955.

Bastos, Elide Rugai. "Um debate sobre o negro no Brasil".São Paulo em Perspectiva, São Paulo, v. 1, nº 5, pp. 20-26, 1988.

Duarte, Paulo. "Negros do Brasil". O Estado de S. Paulo, 16/4/1947, p. 5 . 
Ely, Sylvia Maria Roesch. "Aanálise da implementação de politicas públicas-o caso da lei ${ }^{\circ}$ 6.297/75, de incentivos fiscais à formulação profissional nas empresas". Rev.adm.empres., vol.24, n 4, São Paulo, out./dez.1984.

Faro, J.S. Realidade, 1966-1968. Tempo da reportagem na imprensa brasileira, Canoas: Ed. da ULBRA/AGE, 1999.

Fernandes, Florestan. A integração do negro na sociedade de classes. São Paulo: Cia. Editora Nacional, 1965.

Francisco, Flávio. O novo negro em perspectiva transnacional. Representações afro-americanas sobre o Brasile a França no jornal Chicago Defender (19161940). Tese de doutorado (História Social). USP, São Paulo, 2014.

Fullgraf, Frederico. Fotógrafo brasileiro cobriu secretamente morte de Neruda. 28/5/2013. 〈http://cronopios.com.br/site/colunistas. asp?id=5692>

Gomes, Ângela de Castro. História e historiadores. Rio de Janeiro : Editora Fundação Getulio Vargas, 1999.

Guimarães, Antonio Sérgio A. Classes, raças e democracia. 2. ed. São Paulo: Editora 34, 2012.

Sociologia e natureza:classes, raças e sexos.Document de travail duMage, v. 18, pp. 209-228, 2014.

Guimarães,A.S.A.e Macedo, M. "Diário Trabalhista e democracia racial negra dos anos 1940". Dados, vol. 51, nº 1 , Rio de Janeiro, 2008.

Hellwig, David J. African-American reflections on Brazil's racial paradise. Filadélfia: Temple University, 1992.

Jesus, Carolina Maria de. Quarto de despejo - Diário de uma favelada. São Paulo: Paulo de Azevedo, 1960.

Kosling, Karin. As lutas anti-racistas de afro-descendentes sob vigilância do Deops/SP (1964-1983). Dissertação de mestrado (História Social). USP, 2007.

Langland, Victoria.Speaking offlowers:student movements and the making and remembering of 1968 in military Brazil. Durham: Duke University Press, 2013.

Maciel, Marcos. "A questão étnica no Brasil". Folha de S.Paulo, 22/11/2001.

Maio, Marcos Chor. "Tempo controverso: Gilberto Freyre e o Projeto UNESCO". Tempo Social - Revista de Sociologia da USP. S. Paulo, 11 (1):111-136, maio de 1999.

Malin, Mauro. "JB em 1968". Observatório da Imprensa, edição n ${ }^{\circ}$ $606,7 / 9 / 2010$.

〈http://www.observatoriodaimprensa.com.br/news/impri$\mathrm{mir} / 21837>$

Milliet, Sergio. "O preconceito de cor". O Estado de S. Paulo, 10/5/1947.

Nascimento, Abdias. "Carta a Dacar". Tempo Brasileiro, 9-10, abr-jun 1966:97-106. 
Nogueira, Oracy. Preconceito de marca: as relações raciais em Itapetininga. São Paulo: Edusp 1998; primeira edição de 1955.

Parks, Gordon. "Freedom's fearful foe: poverty". Life Magazine, 1961. Disponível em <http://life.time.com/history/gordon-parks-classic-photo-essay-flavio/\#1>.

Passarinho, Jarbas Gonçalves. Um híbrido fértil. Rio de Janeiro: Expressão e Cultura, 1996.

Queiroz, Rachel de. "Carta aberta ao ministro Jarbas Passarinho". Diário de Notícias, Salvador, 10 e 11/11/1968, p. 4. . "Linha de cor". O Cruzeiro. Rio de Janeiro, 24/5/1947.

Rego, José Lins do. "Paciência, meu branco". O Globo. Rio de Janeiro, 19/4/1947, edição matutina, p.3.

Reston, Tom. Habana. "The OLAS conference defines revolution". The Harvard Crimson, 17/11/1967.

Ridenti, Marcelo. "As oposições à ditadura: resistência e integração". In: Motta, Rodrigo Patto Sá, Reis, Daniel Aarão, e Ridenti, Marcelo (orgs.). A ditadura que mudou o Brasil:50 anos do golpe de 1964. Rio de Janeiro: Jorge Zahar, 2014.

Rios, Flavia. "A trajetória de Thereza Santos: comunismo, raça e gênero durante o regime militar". Plural (São Paulo.Online), [S.l.], v.21, $\mathrm{n}^{\mathrm{O}} 1$, pp. 73-96, jan. 2014 .

Rodrigues, Fernando. "Economista fez autocrítica sobre 1964". Folha de S.Paulo, 11/10/2001. 〈http://pensadoresbrasileiros.home. comcast.net/ pensadoresbrasileiros/RobertoCampos/economista_fez_autocritica_sobre_1964.htm>

Rodrigues, Nina. Os africanos no Brasil.São Paulo: Ed. Nacional, 1932.

Santos, Jocélio Teles. O poder da cultura a cultura no poder. EDUFBA - Scielo Books, 2005.

Silva, Mário Augusto Medeiros da. A descoberta do insólito: literatura negra e literatura periférica no Brasil (1960-2000). Tese de doutorado. Departamento de Sociologia, Unicamp, 2011.

Sotero, Edilza. "Ativismo negro e tentativas de inserção política (1945-1948)". In:Anais do VIII Congresso Brasileiro de Pesquisadores/as Negros/as. Belém, 29 de julho a 2 de agosto de 2014.

Wagley, Charles. The Latin American tradition - Essays on the unity and the diversity of Latin American culture. Nova York: Columbia University Press, 1968.

Weffort, Francisco.Participação e conflito Industrial:Contageme Osasco

\section{NOVOS ESTUDOS}

CEBRAP

101, março 2015

pp. 5-25 1968. Caderno Cebrap. São Paulo: Cebrap, no 5, 1972.

Weinstein, Barbara. "Racializando as diferenças regionais". Revista Esboços, vol.13, nº16, 2006, pp. 281-303. 